\title{
Inhaled Nitric Oxide: In Vitro Analysis of Continuous Flow Noninvasive Delivery via Nasal Cannula
}

\author{
Kineshta Pillay, John Z Chen, Warren H Finlay, and Andrew R Martin
}

\begin{abstract}
BACKGROUND: Inhaled nitric oxide (NO) is most frequently delivered to mechanically ventilated patients in critical care, but it can also be administered noninvasively. The delivered dose and efficiency of continuous flow NO supplied through a nasal cannula has yet to be established. This study aimed to determine the influence of nasal cannula type, supply flow, and breathing pattern on delivered NO using a realistic adult airway replica and lung simulator. METHODS: Simulated breathing patterns were selected to represent rest, sleep, and light exercise, and were varied to investigate the effects of tidal volume and breathing frequency independently. Supplied gas flows targeted tracheal concentrations at rest of 5 or $20 \mathrm{ppm}$ NO and were supplied with 2 $\mathrm{L} / \mathrm{min} \mathrm{O}_{2}$. Three different cannulas were tested. Tracheal NO concentrations and NO mass flow past the trachea were evaluated. RESULTS: Cannula type had a minor influence on delivered dose. Tracheal NO concentrations differed significantly based on breathing pattern $(P<0.01)$; for a target NO concentration of $20 \mathrm{ppm}$ at rest, average inhaled NO concentrations were 23.3 $\pm 0.5 \mathrm{ppm}, 36.5 \pm 1.4 \mathrm{ppm}$, and $17.2 \pm 0.3 \mathrm{ppm}$ for the rest, sleep, and light exercise breathing patterns, respectively. For the same test conditions, mass flow of NO past the trachea was less sensitive to breathing pattern: $20.3 \pm 0.5 \mathrm{mg} / \mathrm{h}, 19.9 \pm 0.8 \mathrm{mg} / \mathrm{h}$, and $24.3 \pm 0.4 \mathrm{mg} / \mathrm{h}$ for the rest, sleep, and light exercise breathing patterns, respectively. Mass flow and delivery efficiency increased when minute volume increased. CONCLUSIONS: These results indicate that inhaled NO concentration is strongly influenced by breathing pattern, whereas inhaled NO mass flow is not. NO mass flow may therefore be a useful dose metric for continuous flow delivery via nasal cannula. Key words: inhaled nitric oxide; constant flow; airway model; nasal cannula; tracheal concentration; mass flow; dose; efficiency. [Respir Care 2021;66(2):228-239. (C) 2021 Daedalus Enterprises]
\end{abstract}

\section{Introduction}

Inhaled nitric oxide (NO) acts as a selective pulmonary vasodilator. ${ }^{1}$ It is conventionally used to treat persistent pulmonary hypertension in the neonatal population and to alleviate pulmonary hypertension in adults and children following cardiac surgery. ${ }^{2-4}$ Use of NO to improve oxygenation in patients with acute lung injury or ARDS has also been studied, though evidence that NO reduces mortality in these patients is lacking. ${ }^{5,6}$ The vast majority of patients receiving

Ms Pillay, Mr Chen, Dr Finlay, and Dr Martin are affiliated with the Department of Mechanical Engineering, University of Alberta, Edmonton, Alberta, Canada.

The authors have disclosed no conflicts of interest.

Ms Pillay presented a version of this paper at the Alberta Biomedical Engineering Conference, held October 25-27, 2019, in Banff, Alberta. inhaled NO therapy do so in the intensive care setting and are simultaneously supported by invasive ventilation..$^{7-9}$ Modern NO delivery devices adapt the rate at which NO-containing source gas is injected into the ventilator breathing circuit in proportion to the flow of gas in the circuit to maintain a constant NO concentration in the inhaled gas mixture, eg, 20 ppm. ${ }^{10-12}$ As such, dosing recommendations for ventilated patients are currently based on the concentration of $\mathrm{NO}$ in the inhaled gas, with dose settings typically ranging from 5-80 ppm for marketed NO delivery devices. ${ }^{6,13}$

In addition to $\mathrm{NO}$ administration to ventilated patients, NO administration to ambulatory, spontaneously breathing

Correspondence: Andrew R Martin PhD PEng, 10-324, Donadeo Innovation Centre for Engineering, University of Alberta, Edmonton, AB T6G 1H9, Canada. E-mail: andrew.martin@ualberta.ca.

DOI: $10.4187 /$ respcare. 07737 


\section{In Vitro Simulation of INO via Nasal Cannula}

patients with pulmonary arterial hypertension or pulmonary hypertension secondary to other lung diseases has been investigated, often in combination with long-term $\mathrm{O}_{2}$ therapy. ${ }^{6,14-16}$ These studies have primarily utilized devices that deliver NO-containing gas through nasal cannula as a short-duration bolus or pulse timed to arrive during the early portion of inhalation. Delivery of gas to the anatomical dead space at the end of inspiration is thereby minimized to conserve the NO-containing source gas and to extend usage times for small, portable gas cylinders with limited capacity. Such an approach is analogous to pulsed $\mathrm{O}_{2}$ delivery widely used by $\mathrm{O}_{2}$-conserving devices. ${ }^{17}$ Pulsed delivery is inherently poorly described using the concentration of NO in the inhaled gas because the concentration is intentionally varied over each inhalation. Thus, comparison with dosing to ventilated patients at constant NO concentration is challenging. Pulsed delivery has instead been described in terms of the mass of NO delivered per breath ${ }^{18}$ or per unit time. ${ }^{19}$

Additional investigational applications of noninvasive NO delivery to spontaneously breathing subjects include delivery through face masks at high concentration (eg, 160 ppm) to cystic fibrosis subjects with persistent mycobacterium infection ${ }^{20}$ and very recently to subjects with COVID$19{ }^{21}$ Delivery through nasal cannula to hemodynamically unstable patients with acute right-ventricular dysfunction has also been used. ${ }^{9}$ Tremblay et $\mathrm{al}^{9}$ recently reported favorable hemodynamic effects in subjects with acute dysfunction receiving noninvasively administered NO. Two thirds of subjects were administered NO in combination with continuous low-flow $\mathrm{O}_{2}$ through nasal cannula. Although such an approach involves supply of a continuous, rather than pulsed, flow of NO-containing gas, for low-flow nasal cannula the entrainment of room air is variable and depends on patient breathing pattern. Therefore, NO concentration in the inhaled gas mixture is not constant, and comparison with $\mathrm{NO}$ dosing done at a constant concentration is difficult.

For an open interface such as a nasal cannula, inhaled $\mathrm{NO}$ concentrations are difficult to measure in vivo because mixing of NO-containing gas with entrained room air occurs during transit through the upper airway. In studies of $\mathrm{O}_{2}$ delivery through nasal cannula, in vitro methods incorporating realistic upper airway replicas and simulated breathing have proven useful, allowing variation in inhaled gas concentrations to be analyzed throughout the breath. ${ }^{22-}$ ${ }^{24}$ Recently, Katz et a ${ }^{24}$ performed in vitro experiments to evaluate volume-averaged tracheal $\mathrm{O}_{2}$ concentrations and volumes of $\mathrm{O}_{2}$ delivered per minute over a wide range of breathing patterns, patient interfaces, and continuous flows. Measured average inhaled $\mathrm{O}_{2}$ concentrations were accurately predicted using a simple calculation of the flowweighted average concentration between the delivered $\mathrm{O}_{2}$ flow and the flow of entrained ambient air. A key variable

\section{QUICK LOOK}

\section{Current knowledge}

Inhaled nitric oxide (NO) is most frequently delivered to mechanically ventilated patients in the critical care setting, but noninvasive administration to spontaneously breathing patients has also been reported. Dosing recommendations for ventilated patients are currently based on the concentration of NO in the inhaled gas. For noninvasive administration through open patient interfaces, such as nasal cannulas, entrainment of room air is variable and depends on the patient's breathing pattern. Therefore, NO concentration in the inhaled gas mixture is not constant, and comparison with NO dosing done at constant concentration is difficult.

\section{What this paper contributes to our knowledge}

Tracheal NO concentration and NO mass flow were assessed for a constant supply flow through a nasal cannula. Measured average inhaled concentrations compared well with flow-weighted predictions that incorporated inhaled tidal volume and inhalation time. Supply flows and patient breathing patterns strongly influenced NO concentrations delivered to the trachea; however, NO mass flow past the trachea showed less sensitivity to changes in breathing parameters. As such, $\mathrm{NO}$ mass flow is a promising dosing metric for delivering inhaled NO via nasal cannula during spontaneous breathing.

in predicting the average inhaled $\mathrm{O}_{2}$ concentration was the average inhalation flow, a function of inhaled tidal volume $\left(\mathrm{V}_{\mathrm{T}}\right)$ and inspiratory time. This result echoes the findings of Duprez et al, ${ }^{25}$ who also recently concluded that the average inspiratory flow has a major impact on average inhaled $\mathrm{O}_{2}$ concentration during $\mathrm{O}_{2}$ delivery at low flow to spontaneously breathing patients.

In this study, we sought to extend these recent in vitro results for low-flow $\mathrm{O}_{2}$ delivery to investigate noninvasive delivery of NO through nasal cannula, under the hypothesis that the dose of NO delivered is sensitive to variations in breathing pattern. Average inhaled NO concentration and inhaled mass of $\mathrm{NO}$ over time (referred to here as inhaled NO mass flow) are reported for co-administration of $\mathrm{NO}$ with $\mathrm{O}_{2}$ over a range of cannula types, simulated breathing patterns, and delivered flows. We compare measured NO concentrations and calculated flow-weighted average concentrations. These results are intended to facilitate an improved comparison between NO delivery at constant flow with established NO dosing at a constant concentration, as well as with newer portable devices designed to deliver a target inhaled mass of NO over time. 


\section{In Vitro Simulation of INO via Nasal Cannula}

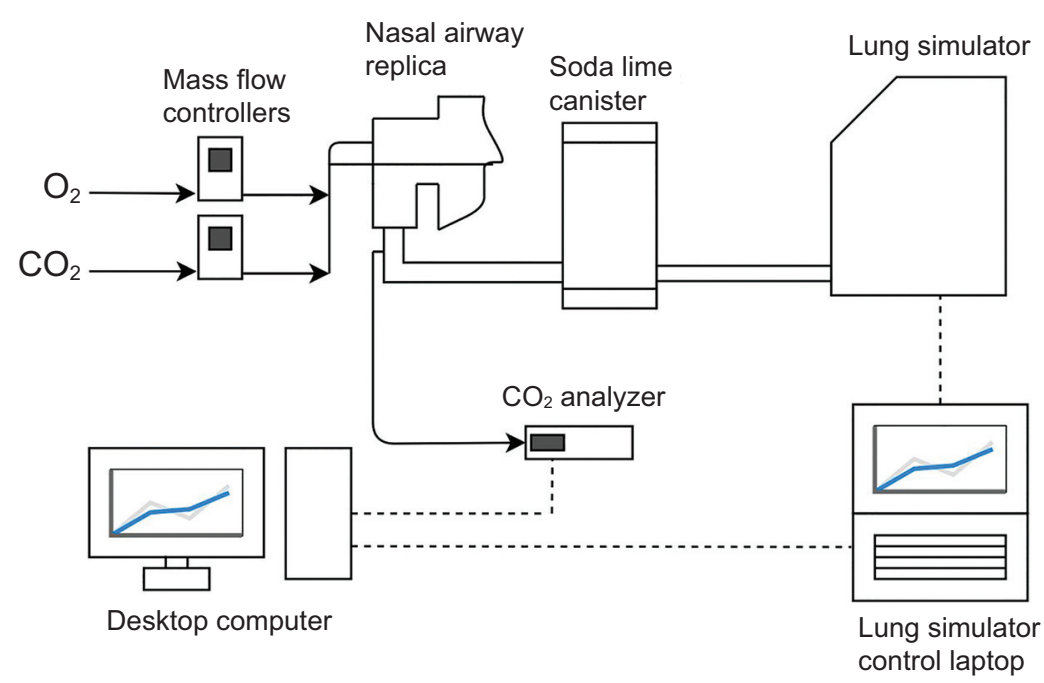

Fig. 1. Experimental setup used to quantify in vitro performance of inhaled $\mathrm{NO}$ delivery through a nasal cannula. $\mathrm{CO}_{2}$ and $\mathrm{O}_{2}$ were supplied from cylinder sources, regulated with mass flow controllers, and delivered through nasal cannula lumen to an airway replica. The nasal airway replica was connected to a mechanical lung simulator via a canister of soda lime, which absorbed the exhaled $\mathrm{CO}_{2}$. The mechanical lung was programmed with breathing patterns to mimic the breathing of an adult with COPD.

\section{Methods}

\section{Nasal Airway Replica}

The nasal airway replica used in this study was identical to that used by Chen et al. ${ }^{23}$ Selection of this replica was based on the criterion that the volume-averaged $\mathrm{F}_{\mathrm{IO}_{2}}$ obtained using the replica was closest to average values obtained in earlier work across a set of 15 replicas. $^{22}$ The nasal airway was derived from images of a female adult subject, for whom nasal airways were deemed normal by a radiologist. Furthermore, because intersubject variability among 15 airway replicas had only a small impact $(5 \%$ coefficient of variation) on volume-averaged $\mathrm{F}_{\mathrm{IO}_{2}}$, the use of a single representative replica was deemed reasonable. ${ }^{23}$ As described previously, the airway replica used in this study was built in acrylic plastic using rapid prototyping, which was based on magnetic resonance images and included airway passages from the nares through the entrance to the trachea, excluding the oral cavity. ${ }^{22,23}$ The imaging used in the construction of the replica was obtained with University of Alberta Health Research Ethics Board approval. $^{26}$ Airway dimensions for the replica were obtained using MeshLab (Visual Computing Laboratory, Istituto di Scienza e Tecnologie dell'Informazione, Pisa, Italy) and ParaView (Kitware, Clifton Park, New York). ${ }^{22}$ The selected replica had an interior wall surface area of 287 $\mathrm{cm}^{2}$ and a total interior volume of $44.6 \mathrm{~mL} .^{22}$

\section{Experimental Apparatus}

The nasal airway replica was connected to a mechanical lung simulator to provide an in vitro model for assessment of NO delivery. Figure 1 displays a schematic of the experimental apparatus used in this study. As permitted in FDA guidance, ${ }^{27} \mathrm{CO}_{2}$ was used as a surrogate gas to simulate the delivery of NO. Gas transport through the upper and central airways is dominated by convection rather than diffusion. ${ }^{18}$ As such, the different diffusivity of $\mathrm{CO}_{2}$ and $\mathrm{NO}$ is inconsequential in these conditions. Furthermore, mixed $\mathrm{CO}_{2}$ concentrations in air/ $\mathrm{O}_{2}$ were $<6 \%$ in all cases, such that influence of $\mathrm{CO}_{2}$ on the mixture density was small. Flows of $\mathrm{CO}_{2}$ and $\mathrm{O}_{2}$ (Praxair Canada, Mississauga, Ontario, Canada) were supplied simultaneously to the nasal airway replica via nasal cannula. The flow of each gas from the cylinder source through the cannula was regulated by separate mass flow controllers calibrated for $\mathrm{CO}_{2}$ (Alicat $\mathrm{MC}$ 2SLPM-D/5M; Alicat Scientific, Tucson, Arizona) and for $\mathrm{O}_{2}$ (Alicat MC-20SLPM-D/5M; Alicat Scientific). Each mass flow controller adjusted the flow from the cylinder source with a 30-ms control response and was factory calibrated for an accuracy of $\pm 0.6 \%$ of the reading.

Breathing through the replica was simulated using a programmable lung simulator (ASL 5000 Breathing Simulator; IngMar Medical, Pittsburgh, Pennsylvania) operated in flow pump mode. The nasal airway replica outlet was connected to a soda lime canister (Spherasorb; Intersurgical, Berkshire, United Kingdom) using a plastic breathing circuit tube with a 22-mm internal diameter and a total internal volume of 135 $\mathrm{cm}^{3}$. This volume was selected to be representative of the conducting airway volume from the trachea to the gasexchange regions of the lungs for an average adult with a function residual capacity of $3 \mathrm{~L}^{28}$ The canister of soda lime was used to absorb all $\mathrm{CO}_{2}$ passing through the replica and conducting airway tubing, mimicking an assumed absolute uptake of NO in the gas exchange regions of the lung. ${ }^{10,15}$ 


\section{In Vitro Simulation of INO via Nasal Cannula}

Table 1. Reproduced Breathing Pattern Parameters*

\begin{tabular}{lcccccc}
\hline \hline $\begin{array}{c}\text { Breathing } \\
\text { Pattern }\end{array}$ & $\begin{array}{c}\text { Tidal Volume, } \\
\mathrm{mL}\end{array}$ & $\begin{array}{c}\text { Inspiratory } \\
\text { Time, } \mathrm{s}\end{array}$ & $\begin{array}{c}\text { Expiratory } \\
\text { Time, } \mathrm{s}\end{array}$ & $\begin{array}{c}\text { Breathing Frequency, } \\
\text { breaths/min }\end{array}$ & $\begin{array}{c}\text { Inspiratory Time/ } \\
\text { Expiratory Time }\end{array}$ & $\begin{array}{c}\text { Inspiratory Time/Total } \\
\text { Time }\end{array}$ \\
\hline Rest & 640 & 1.2 & 2.33 & 17 & 0.52 & 0.34 \\
Exercise & 800 & 0.96 & 1.77 & 22 & 0.54 & 0.35 \\
Sleep & 520 & 1.79 & 2.93 & 13 & 0.61 & 0.38
\end{tabular}

* Parameters were selected to reflect an adult subject with COPD.

Preliminary experiments were performed to confirm that use of a 3.6-L canister filled with soda lime was sufficient for absorption of all $\mathrm{CO}_{2}$ arriving at the canister. The soda lime was replaced at intervals when a color change showing saturation in the chemical was noted or when the $\mathrm{CO}_{2}$ concentration measured in real time was too high.

The $\mathrm{CO}_{2}$ concentration was sampled using a sidestream infrared analyzer (GA-200; iWorx, Dover, New Hampshire) at the exit of the airway replica. Data output from the analyzer was processed with LabVIEW data acquisition software (National Instruments, Austin, Texas), which recorded volumetric data from the lung simulator simultaneously.

\section{Breathing Pattern Simulation}

Three breathing patterns were selected to provide an approximation of the variability in respiration that an average patient might experience in a day. These patterns mimic the respiratory patterns from a patient at rest, doing light exercise, and while sleeping; these patterns were based on data from studies of subjects with COPD receiving supplemental oxygen. ${ }^{29,30}$ Parameters used to define each breathing pattern are provided in Table 1. Inhalation and exhalation cycles both followed a half-sinusoidal shape. The volume of the test lung chamber was logged during breathing at a sampling frequency of $512 \mathrm{~Hz}$ using the ASL 5000 software.

In addition to the breathing patterns defined in Table 1, further experiments were conducted at $\mathrm{V}_{\mathrm{T}}=520 \mathrm{~mL}$ and a breathing frequency of 22 breaths/min, and at $\mathrm{V}_{\mathrm{T}}=800$ $\mathrm{mL}$ and a breathing frequency of 13 breaths $/ \mathrm{min}$. Combined with experiments conducted using the rest, exercise, and sleep patterns, these measurements allowed the influence of $\mathrm{V}_{\mathrm{T}}$ and frequency to be assessed independently, with all other parameters held constant.

\section{Nasal Cannula Types}

To investigate any potential differences in gas delivery across different cannula types, 3 cannulas were used (shown schematically in Fig. 2): (1) a single-lumen cannula (1103; Hudson RCI, Teleflex Medical, Research Triangle Park, North Carolina) where flows of $\mathrm{O}_{2}$ and $\mathrm{CO}_{2}$ were

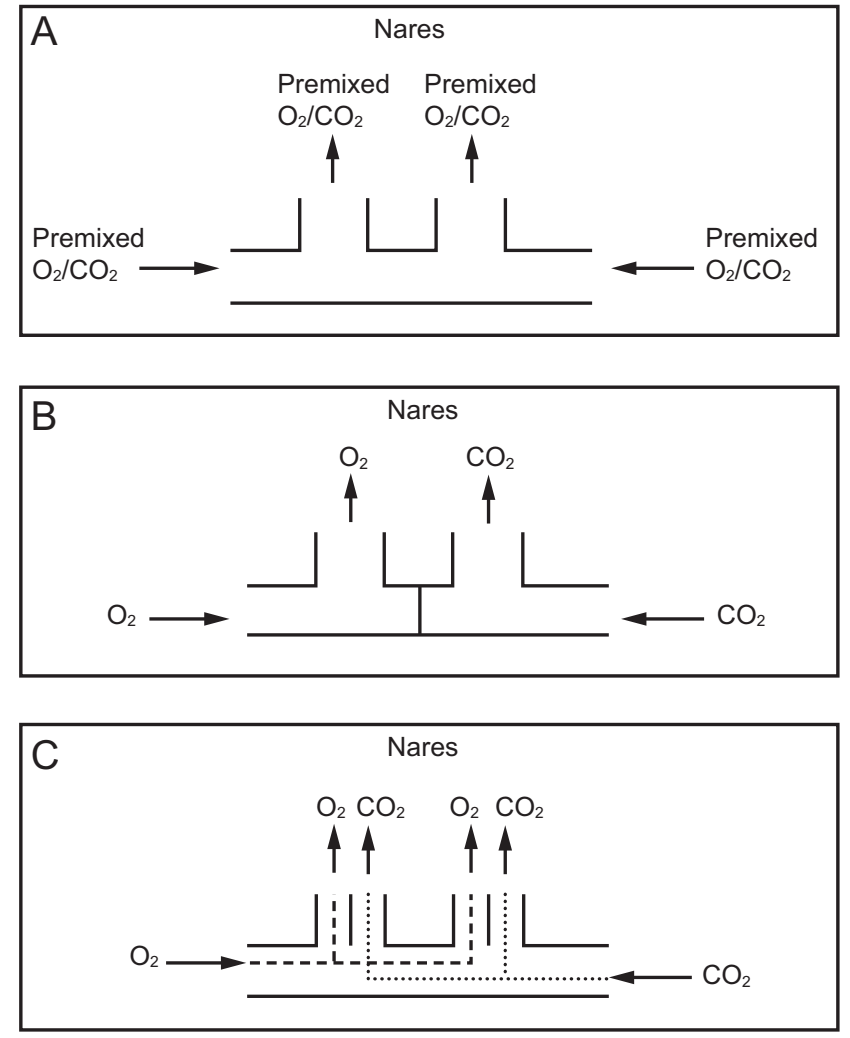

Fig. 2. Cannula types utilized in experiments: A: a single-lumen cannula with premixed gases upstream, B: a dual-lumen cannula with different gases supplied to each nostril, and C: a dual-lumen cannula with both gases (while separated) supplied to each nostril.

pre-mixed using a Y-connector positioned upstream from the cannula; (2) a dual-lumen cannula with a different gas going into each nostril (4807-7-7; Salter Labs, Carlsbad, California); and (3) a dual-lumen cannula with the gases separated until entering the nares (1165011; Intersurgical).

\section{Gas Flows and Concentration Measurements}

As noted above, $\mathrm{CO}_{2}$ was used as a surrogate gas to simulate the delivery of NO. To prescribe flows of $\mathrm{CO}_{2}$ for the experimental protocol, corresponding flows of source NOcontaining gas were first defined. Continuous NO flows were selected to target average concentrations of $20 \mathrm{ppm}$ 


\section{In Vitro Simulation of INO via Nasal Cannula}

and $5 \mathrm{ppm} \mathrm{NO}$ at the trachea for the resting breathing pattern. These flows were calculated using the following equation, based on an assumption of complete mixing of the NO flow within the inspired breath ${ }^{24}$ :

$$
\mathrm{Q}_{\mathrm{NO}}=\left(\mathrm{V}_{\mathrm{T}} / \mathrm{T}_{\mathrm{i}}\right) \times(\mathrm{FtNO} / 800 \mathrm{ppm})
$$

where $\mathrm{Q}_{\mathrm{NO}}$ is the supplied $\mathrm{NO}$ flow, $\mathrm{T}_{\mathrm{i}}$ is the inspiratory time, FtNO is the targeted average NO concentration at the trachea (in ppm), and the concentration of NO in the source gas is assumed to be $800 \mathrm{ppm}$, consistent with the concentration of NO in supply gas cylinders in North America.

Flows of 0.8 and $0.2 \mathrm{~L} / \mathrm{min}$ of $800 \mathrm{ppm} \mathrm{NO}$ were calculated using this equation to target average concentration of 20 and 5 ppm, respectively, for the resting breathing pattern. Flows of $\mathrm{CO}_{2}$ supplied in the experiments were set equal to these values, with $100 \% \mathrm{CO}_{2}$ representing 800 ppm NO. $\mathrm{CO}_{2}$ concentrations were sampled at the exit of the replica (ie, the trachea), and were corrected for sampling delay and time constant. The $\mathrm{CO}_{2}$ concentration was sampled at a flow of $200 \mathrm{~mL} / \mathrm{min}$, which is 2 orders of magnitude smaller than average inhalation flows and as such is not expected to have any appreciable influence on flow through the replica and lung simulator. To determine the time constant of the sampling system, preliminary experiments were conducted in which the gas supply to the analyzer was rapidly switched between 2 different gas mixtures of known concentration $\left(0 \%\right.$ and $\left.100 \% \mathrm{CO}_{2}\right)$. A time constant of $223 \mathrm{~ms}$ was calculated and applied to correct the $\mathrm{CO}_{2}$ concentration recorded over time following methods described in Langer et $\mathrm{al}^{31}$ and adopted previously by Chen et al. ${ }^{22}$ The volumetric flow of $\mathrm{CO}_{2}$ passing the trachea was then determined by multiplying the known inspiratory flow with $\mathrm{CO}_{2}$ concentration. The trapezoidal rule was used to integrate the $\mathrm{CO}_{2}$ flow over each inhalation $(\Delta t=29 \mathrm{~ms})$ to determine the volume of $\mathrm{CO}_{2}$ inhaled per breath. After following a similar procedure to determine the measured $\mathrm{V}_{\mathrm{T}}$, a volume-averaged value for the concentration of $\mathrm{CO}_{2}$ per breath was found by dividing the volume of $\mathrm{CO}_{2}$ by $\mathrm{V}_{\mathrm{T}}$. Using a conversion factor of $100 \%$ $\mathrm{CO}_{2}=800 \mathrm{ppm} \mathrm{NO}$, the corresponding inhaled NO concentration was then calculated. Results are reported in terms of these corresponding NO values. All measurements were conducted approximately 60 breathing cycles after supply gas flows were started, which allowed the system to reach steady state as confirmed by observing real-time gas concentration waveforms.

Experimental NO concentrations were compared to predicted concentrations. Predicted values were calculated using:

$$
[\mathrm{NO}]_{\text {predicted }}=\left(800 \mathrm{ppm} \times \mathrm{Q}_{\mathrm{NO}}\right) /\left(\mathrm{V}_{\mathrm{T}} / \mathrm{T}_{\mathrm{i}}\right) .
$$

The mass flow of NO represents the mass of the gas delivered past the trachea over time, similar to an inhaled minute volume of $\mathrm{NO}$, and is an alternate form of assessing dose delivery. Mass flow past the trachea was calculated from the following equation:

Mass flow $=[\mathrm{NO}]_{\text {trachea }} \times \mathrm{V}_{\mathrm{T}} \times$ breathing frequency $\times \rho_{\mathrm{NO}}$

where $\rho_{\mathrm{NO}}=1.34 \mathrm{~kg} / \mathrm{m}^{3}$ at $20^{\circ} \mathrm{C}$ and $1 \mathrm{~atm}$. Efficiency of delivery $(\eta)$ to the trachea was evaluated as the ratio of measured tracheal NO mass flow to supplied NO mass flow.

\section{Experimental Design}

Experiments were conducted with flows of $0.2 \mathrm{~L} / \mathrm{min}$ and $0.8 \mathrm{~L} / \mathrm{min} \mathrm{CO}_{2}$ and a supplementary $\mathrm{O}_{2}$ flow of 2 $\mathrm{L} / \mathrm{min}$. Three breathing patterns (sleep, rest, and exercise) were used, and tests were run with all 3 cannulas. Then additional experiments were conducted using only 1 cannula (Intersurgical) across the 3 breathing patterns and both $\mathrm{CO}_{2}$ flows, but at an $\mathrm{O}_{2}$ flow of $6 \mathrm{~L} / \mathrm{min}$. A final set of experiments was performed to independently vary $\mathrm{V}_{\mathrm{T}}$ and breathing frequency. Using 1 nasal cannula, the breathing frequency for the sleep and exercise breathing patterns were exchanged while maintaining the original $\mathrm{V}_{\mathrm{T}}$.

For each experimental condition, 3 replicate tests were executed, and for each replicate the inhaled NO concentration was determined as the average of 5 consecutive breaths. Measurement uncertainty for $[\mathrm{NO}]_{\text {trachea }}$ reported below is estimated as 1 standard deviation across replicate tests. Uncertainty for NO mass flow and efficiency $(\eta)$ was calculated by propagating error using standard error analysis techniques. ${ }^{32}$ Variability between average NO concentrations obtained on separate days and from different points on the circumference of the trachea base were found to be of similar magnitude as the variation between individual breaths.

\section{Statistical Analysis}

Multiple 2-factor analysis of variance tests were performed to compare the influences of cannula and breathing pattern on average NO concentration and NO mass flow. Two separate analysis of variance tests were executed for each flow $(0.2 \mathrm{~L} / \mathrm{min}$ and $0.8 \mathrm{~L} / \mathrm{min}$ of $800 \mathrm{ppm}$ NO supply). A significance level of alpha $=0.05$ was used. Tukey post hoc analyses were performed. Unpaired 2-tailed Student $t$ tests were also performed to assess the impact of varying supplemental $\mathrm{O}_{2}$ flows on $\mathrm{NO}$ concentration. Additional unpaired 2-tailed Student $t$ tests were conducted to compare relative influences of NO flow on efficiency. Post hoc analyses were performed using VassarStats (Vassar College, New York), and the remainder of the statistical analysis was performed in Excel (Microsoft, Redmond, Washington). 


\section{In Vitro Simulation of INO via Nasal CanNula}

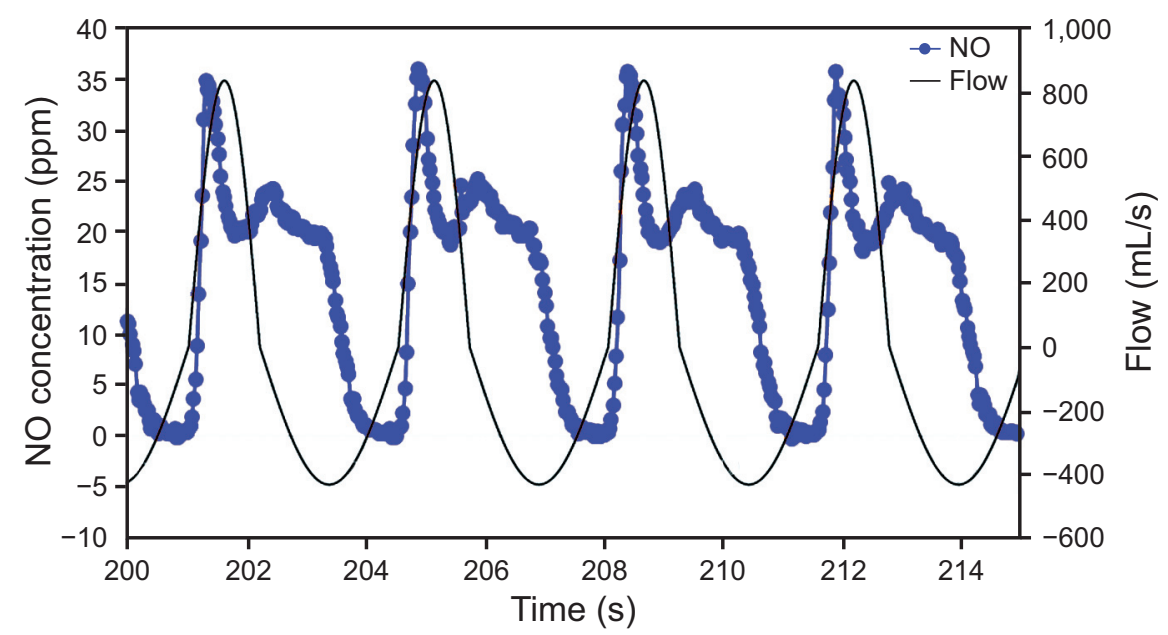

Fig. 3. Sample NO concentration and total flow past the trachea recorded during the data-acquisition process for $0.8 \mathrm{~L} / \mathrm{min}$ of $800 \mathrm{ppm} \mathrm{NO}$ supply at rest with $2 \mathrm{~L} / \mathrm{min}$ supplemental $\mathrm{O}_{2}$. NO concentration drops toward zero at the end of each breath because any NO not absorbed is exhaled.

\section{Results}

Because $\mathrm{CO}_{2}$ was used to simulate $\mathrm{NO}$, the results are presented as NO. Tracheal NO concentration waveforms displayed a consistent shape across all parameters studied, as exemplified in Figure 3. The first, taller peak indicates pooling in the airways at the end of expiration. Because NO flow is supplied continuously throughout the breath, it accumulates in the upper airways as exhalation ends and the expiratory flow approaches zero. This pooled NO is then inhaled at the start of the next inspiration, which is reflected in the sharp peak in concentration. Once the pooled NO is inhaled, the inspiration flow then increases toward a maximum, so correspondingly the fraction of inhaled gas represented by NO decreases, which is reflected in a decline in NO concentration. Conversely, as the inspiration flow passes its peak and begins to decrease again, the NO fraction in the inhaled gas increases. As exhalation begins, gas remaining in the dead space between the airway replica and test lung is the first to be exhaled. The NO concentration decreases as the dead space gas is exhaled. As exhalation proceeds, the NO concentration approaches zero, reflecting complete absorption in the simulated peripheral lung region.

\section{NO Concentration}

Volume-averaged tracheal NO concentrations were highest for the sleep breathing pattern and lowest for the pattern representing exercise. Consistent trends were observed for the low and high supply flows, with delivered NO concentrations higher for the high supply flow than for the low supply flow. Figure 4 and Figure 5 show the average NO concentrations during inhalation for varied $\mathrm{NO}$ and $\mathrm{O}_{2}$ supply flows. Influences of cannula type and breathing pattern were statistically significant $(P<.001)$. Post hoc analysis confirmed the consistent significance of breathing pattern across all pairs of data $(P<.01)$. While influence of cannula type was statistically significant (in 10 of 18 pairs of data by post hoc analysis, $P<.05$ ), differences observed between cannula types were small (effect size was $0.2-0.8 \%$ ) in comparison to differences observed between breathing patterns (effect size was 98.5-99.1\%). When averaged over the 3 cannula types, average inhaled tracheal NO concentrations were $23.3 \pm 0.5 \mathrm{ppm}, 36.5 \pm$ $1.4 \mathrm{ppm}$, and $17.2 \pm 0.3 \mathrm{ppm}$, for the rest, sleep, and light exercise breathing patterns, respectively, for the case of a target $\mathrm{NO}$ concentration of $20 \mathrm{ppm}$ at rest (Fig. 4).

In 5 of 6 cases, differences between average inhaled tracheal NO concentration for the $2 \mathrm{~L} / \mathrm{min}_{2}$ flow versus the $6 \mathrm{~L} / \mathrm{min} \mathrm{O}_{2}$ flow were statistically significant $(P<.05)$. Supplying a higher $\mathrm{O}_{2}$ flow resulted in lower NO concentrations; however, these effects were again small in comparison to differences observed between breathing patterns (Fig. 4, Fig. 5).

Average inhaled tracheal NO concentrations were slightly higher than those predicted using Equation 2, with the greatest deviation in delivery being for the exercise breathing pattern and the closest agreement to the prediction being for the sleep pattern, as can be seen in Figure 6 . In all cases, inhaled tracheal NO concentrations were predicted within $\pm 4.5 \mathrm{ppm}$.

\section{Mass Flow past the Trachea}

Inhaled NO mass flow was highest for the exercise breathing pattern $(P<.01$ for all post hoc data pairs between exercise and other breathing patterns), and 


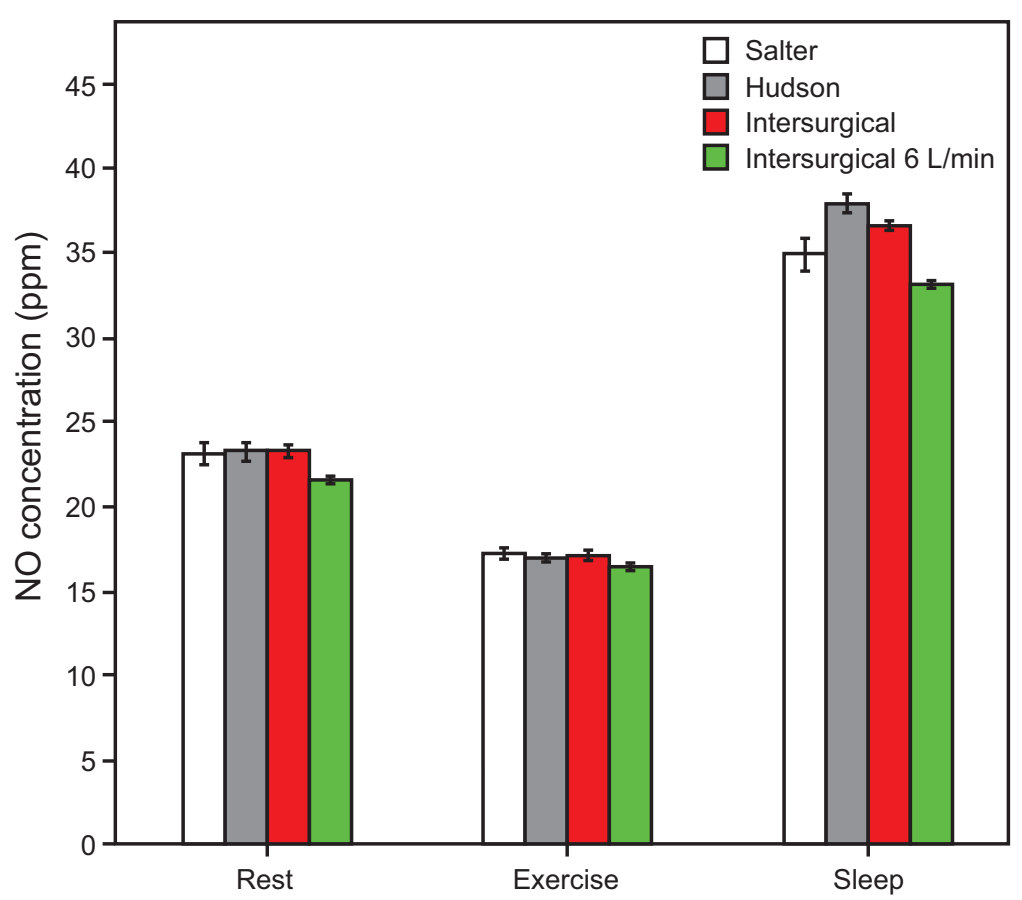

Fig. 4. Average inhaled NO concentration at the trachea for $0.8 \mathrm{~L} / \mathrm{min}$ of $800 \mathrm{ppm}$ NO supply, presented by breathing pattern. Unless otherwise indicated, columns represent average tracheal $\mathrm{NO}$ concentration at $2 \mathrm{~L} / \mathrm{min}$ supplemental $\mathrm{O}_{2}$ with respective cannulas.

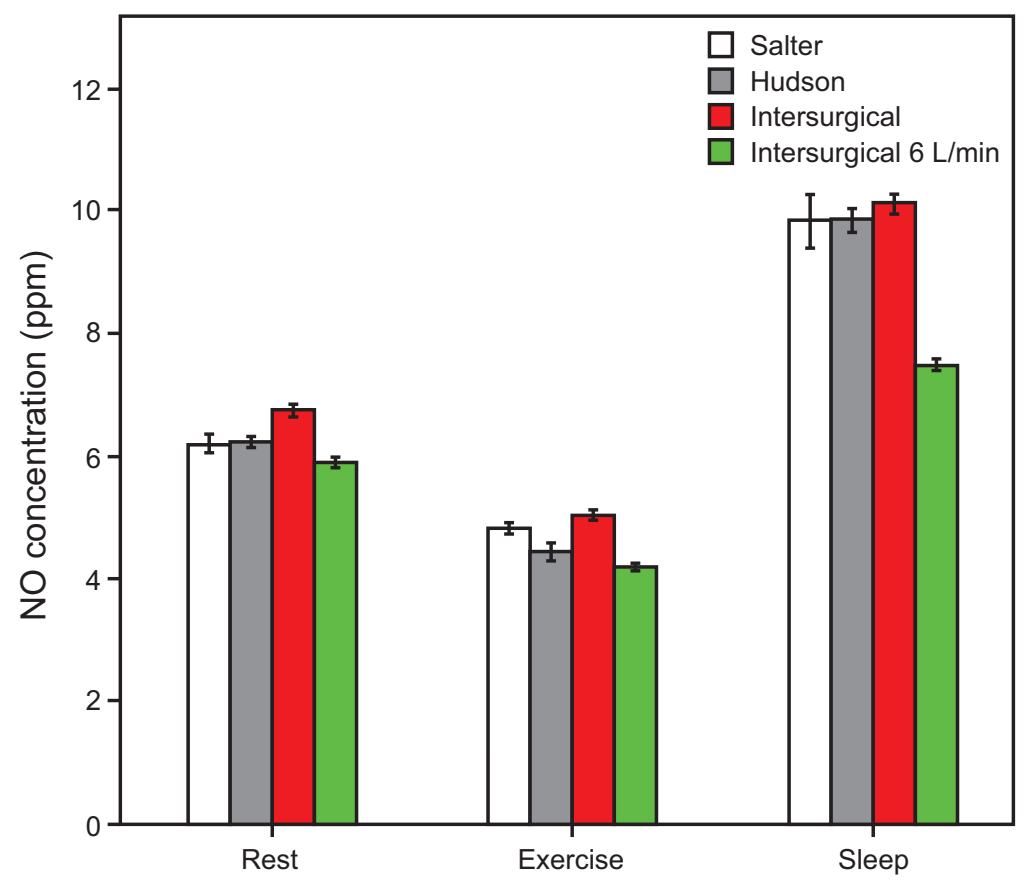

Fig. 5. Average inhaled NO concentration at the trachea for $0.2 \mathrm{~L} / \mathrm{min}$ of $800 \mathrm{ppm} \mathrm{NO}$ supply, presented by breathing pattern. Unless otherwise indicated, columns represent average tracheal $\mathrm{NO}$ concentration at $2 \mathrm{~L} / \mathrm{min}$ supplemental $\mathrm{O}_{2}$ with respective cannulas.

comparable between sleep and rest patterns $(P>.05$ for 3 of 6 post hoc data comparisons). Figure 7 and Figure 8 show inhaled $\mathrm{NO}$ mass flow for varied $\mathrm{NO}$ and $\mathrm{O}_{2}$ supply flows and for different breathing patterns. The influences of breathing pattern $(P<.001)$ and cannula type $(P<.05)$ were both statistically significant. Differences observed between cannula types were small (effect size $0.9-9.5 \%$ ) in comparison to differences observed between breathing patterns (effect size 83.4-94.5\%). Post hoc analysis confirmed the significance of breathing pattern between sleep and 


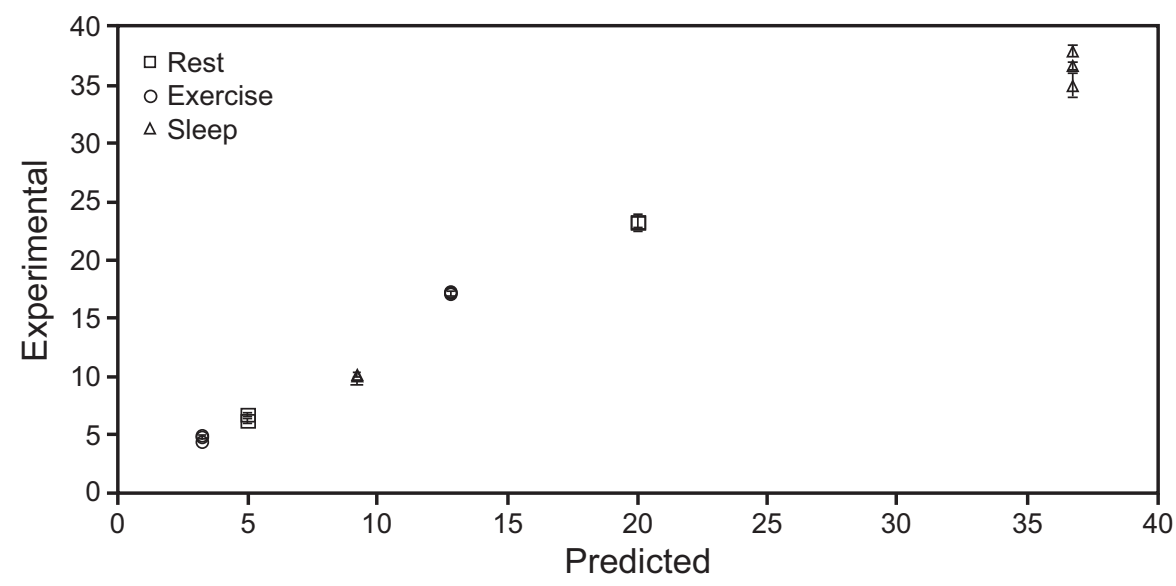

Fig. 6. Differences between the experimental and predicted NO concentrations at the trachea, separated by breathing pattern. Measured NO concentration was best predicted for the sleep breathing pattern while rest and exercise were progressively poorly predicted. Sleep had the highest concentrations, and exercise had the lowest. Each point represents the average (no. =15) for a single flow, breathing pattern, and cannula type.

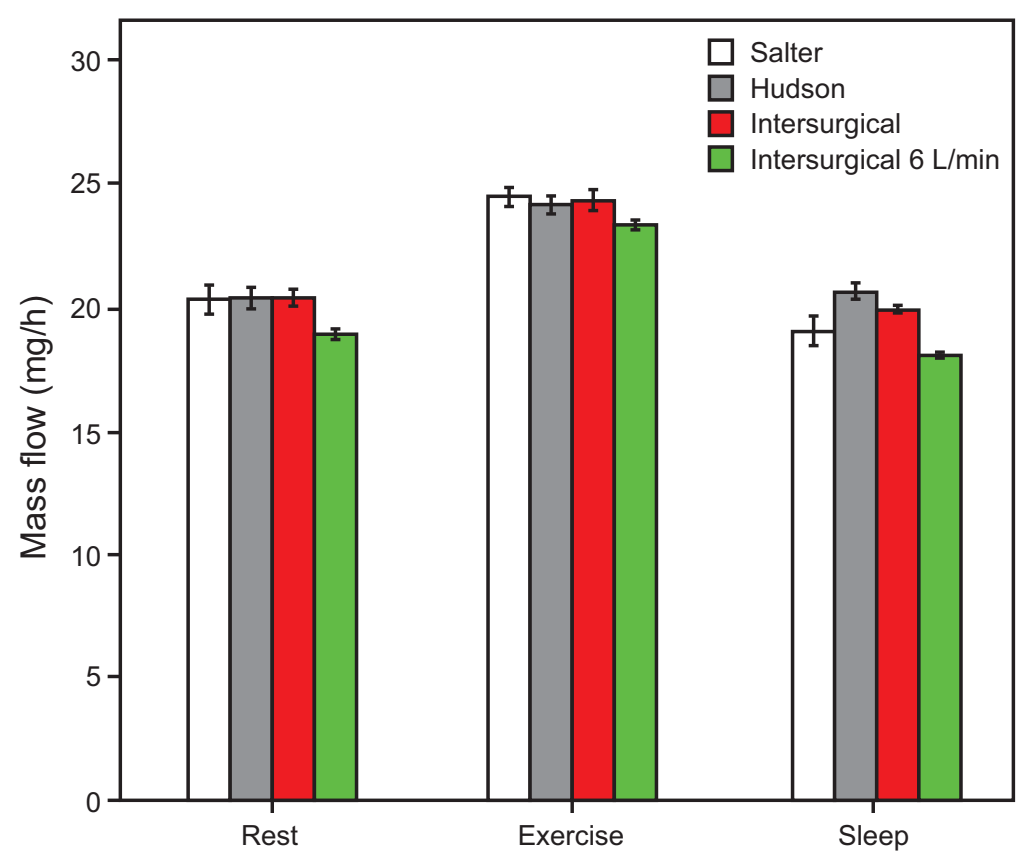

Fig. 7. Mass flow per breath past the trachea for $0.8 \mathrm{~L} / \mathrm{min}$ of $800 \mathrm{ppm}$ NO supply, presented by breathing pattern. Unless otherwise indicated, columns represent average tracheal $\mathrm{NO}$ concentration at $2 \mathrm{~L} /$ min supplemental $\mathrm{O}_{2}$ with respective cannulas.

exercise, and between rest and exercise $(P<.01)$. Between rest and sleep, 3 of 6 results showed significance $(P<.01)$; however, relative differences in NO mass flow across breathing patterns were much smaller than those in NO concentration. At the higher supply flow (Fig. 7), when averaged over the 3 cannula types, mass flow of NO past the trachea was $20.3 \pm 0.5 \mathrm{mg} / \mathrm{h}, 19.9 \pm 0.8 \mathrm{mg} / \mathrm{h}$, and $24.3 \pm 0.4 \mathrm{mg} / \mathrm{h}$ for the rest, sleep, and light exercise breathing patterns, respectively.
In 5 of 6 cases, differences between inhaled NO mass flow for the $2 \mathrm{~L} / \mathrm{min} \mathrm{O}_{2}$ flow versus $6 \mathrm{~L} / \mathrm{min} \mathrm{O}_{2}$ flow were statistically significant $(P<.05)$. Supplying a higher $\mathrm{O}_{2}$ flow resulted in lower NO mass flow at the trachea.

\section{Delivery Efficiency}

Delivery efficiency depended on both breathing pattern and supply flow. The delivery efficiencies at the high NO 


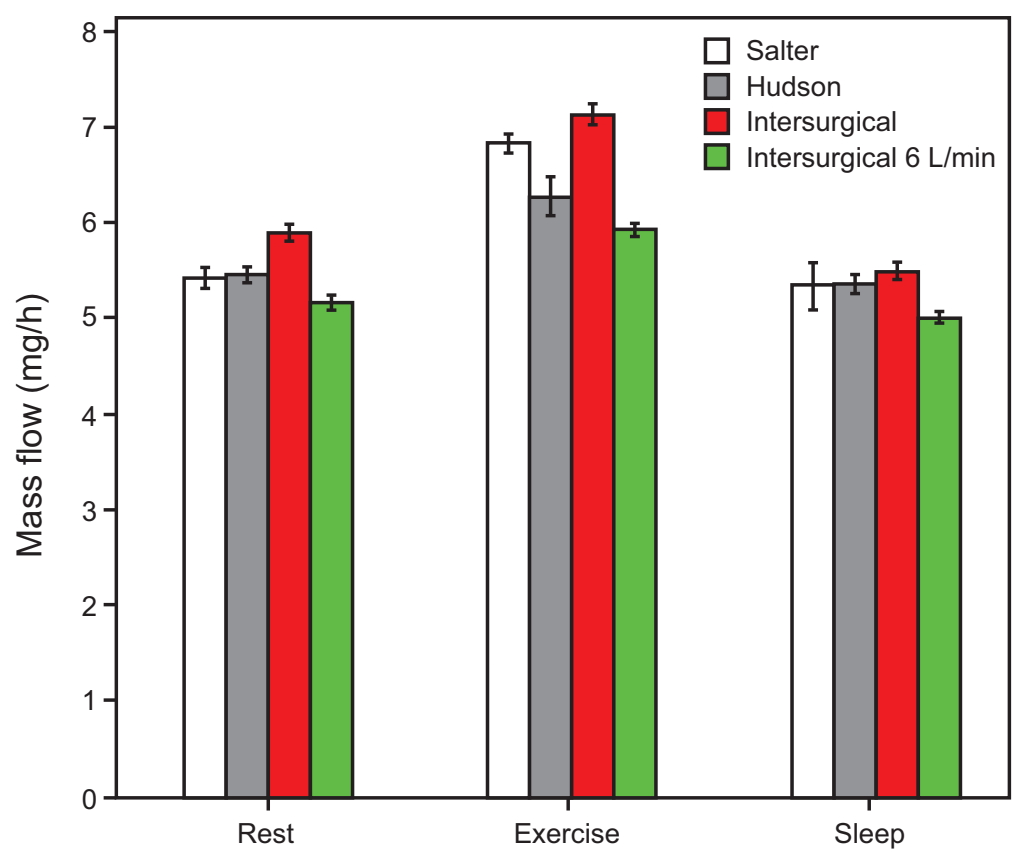

Fig. 8. Mass flow per breath past the trachea for $0.2 \mathrm{~L} / \mathrm{min}$ of $800 \mathrm{ppm}$ NO supply, presented by breathing pattern. Unless otherwise indicated, columns represent average tracheal $\mathrm{NO}$ concentration at $2 \mathrm{~L} /$ min supplemental $\mathrm{O}_{2}$ with respective cannulas.

supply flow averaged $37-47 \%$, whereas efficiencies at the low NO supply rate averaged $40-53 \%$. Seven of $9 t$ tests comparing efficiencies at high versus low NO supply flows were statistically significant $(P<.05)$.

For both high and low NO supply flows, the exercise pattern showed the highest delivery efficiency, and sleep and rest had comparable efficiencies. To evaluate whether these differences could be attributed to variation in $\mathrm{V}_{\mathrm{T}}$ or breathing frequency, additional experiments were conducted to vary these 2 parameters independently. These experiments were conducted with the high NO supply flow. When the breathing frequency decreased from 22 to 13 breaths/min with $\mathrm{V}_{\mathrm{T}}$ held constant at $800 \mathrm{~mL}$, mass flow dropped by 4 $\mathrm{mg} / \mathrm{h}$ and the efficiency dropped by an absolute value of $8 \%$. Conversely, when the breathing frequency increased from 13 to 22 breaths/min with a $V_{T}$ of $520 \mathrm{~mL}$, mass flow increased by $2 \mathrm{mg} / \mathrm{h}$ and the efficiency increased by $5 \%$. When $\mathrm{V}_{\mathrm{T}}$ was decreased from $800 \mathrm{~mL}$ to $520 \mathrm{~mL}$ at a breathing frequency of 22 breaths/min, the mass flow dropped by $2 \mathrm{mg} / \mathrm{h}$ and the efficiency dropped by an absolute value of $4 \%$. Conversely, when $\mathrm{V}_{\mathrm{T}}$ was increased from 520 $\mathrm{mL}$ to $800 \mathrm{~mL}$ at a breathing frequency of 13 breaths/min, the mass flow increased by only $0.5 \mathrm{mg} / \mathrm{h}$ and the efficiency increased by $1 \%$.

\section{Discussion}

This study evaluated the NO dose delivered at continuous flow through a nasal cannula across a range of supply flows, breathing patterns, and cannula types. Delivery parameters were selected to reflect emerging clinical applications, and results were presented across different dose metrics, including NO concentration, which is currently used in the critical care setting, and NO mass flow, which is under investigation for long-term $\mathrm{NO}$ administration. Average inhaled NO concentrations measured at the trachea were reasonably well predicted using a flow-weighted calculation to account for dilution of delivered NO by entrained ambient air. Variability in the inhaled NO dose with breathing pattern was much greater when assessed as an average inhaled concentration versus as a mass flow over time.

Delivery of NO in combination with continuous flow $\mathrm{O}_{2}$ was assessed for 3 different nasal cannula designs. As shown schematically in Figure 2, for the single-lumen Hudson cannula, flows of $\mathrm{O}_{2}$ and $\mathrm{CO}_{2}$ (used as a surrogate for $\mathrm{NO}$ ) were combined using a $\mathrm{Y}$-connector positioned upstream from the cannula; for the 2 dual-lumen designs (Salter and Intersurgical) $\mathrm{CO}_{2}$ and $\mathrm{O}_{2}$ were supplied via individual lumen. Differences in inhaled NO concentration and mass flow between cannula types were small in all cases studied and were not considered to be clinically important. These data suggest that mixing of the 2 supplied gas streams with entrained air within the nasal airways was efficient, such that no advantage or disadvantage was observed when comparing against the premixed, singlelumen case. Nevertheless, use of a dual-lumen cannula may confer other advantages; it is notable that using a duallumen interface, which keeps $\mathrm{NO}$ and $\mathrm{O}_{2}$ flows separate up to entering the nasal airways, decreases production of 


\section{In Vitro Simulation of INO via Nasal Cannula}

nitrogen dioxide $\left(\mathrm{NO}_{2}\right)$, a potentially harmful byproduct formed by reaction of $\mathrm{NO}$ and $\mathrm{O}_{2}$. Of the 2 dual-lumen cannulas investigated here, only the Intersurgical cannula delivered both $\mathrm{NO}$ and $\mathrm{O}_{2}$ to each nostril, which could be advantageous in circumstances where one nostril is congested or occluded. For these reasons, a dual-lumen cannula that delivers $\mathrm{NO}$ and $\mathrm{O}_{2}$ to each nostril (such as the Intersurgical cannula evaluated in this study) is recommended for continuous flow delivery of NO in combination with supplemental $\mathrm{O}_{2}$.

The feasibility of noninvasive, continuous flow administration of NO via nasal cannula has recently been demonstrated by Tremblay et $\mathrm{al}^{9}$ in hemodynamically unstable subjects with acute right-ventricular dysfunction. Two thirds of the subjects were administered NO in combination with continuous low-flow oxygen, at a median flow of 2 $\mathrm{L} / \mathrm{min}$, through nasal cannula. Noninvasively administered NO was associated with favorable hemodynamic effects in these subjects and circumvented the hemodynamically deleterious effects of tracheal intubation. ${ }^{9}$ Tremblay et $\mathrm{al}^{9}$ reported delivery of $\mathrm{NO}$ at concentrations between 20 and $40 \mathrm{ppm}$, presumably reported as the concentration of NO in gas delivered to the cannula, prior to dilution by entrained room air. As our results indicate, average inhaled NO concentrations at the trachea are considerably lower and vary with patient breathing pattern. Given the current need for additional prospective studies to evaluate the dose-dependent response to noninvasive nasal $\mathrm{NO},{ }^{33}$ accurate predictions of average inhaled NO concentrations are critical. In a previous in vitro study assessing NO delivery across multiple delivery interfaces, DiBlasi et $\mathrm{al}^{34}$ reported the challenge of predicting delivery through an open interface. In this study, the average inhaled tracheal NO concentration for a constant flow of a fixed concentration showed wide variation across both breathing pattern and supply flow. The sleep breathing pattern, which produced low minute volumes, resulted in an average tracheal NO concentration (36.5 ppm at higher NO supply flow versus $9.9 \mathrm{ppm}$ at lower NO supply flow) more than double that of the exercise breathing pattern (17.2 ppm at higher flow versus 4.8 ppm at lower flow). This indicates that the tracheal concentration of the delivered gas is strongly influenced by breathing pattern, a result corroborated by similar studies of continuous flow $\mathrm{O}_{2}$ delivery. ${ }^{24,25}$ Reasonably predictive estimates for the average inhaled concentration at the trachea $( \pm 4.5 \mathrm{ppm} \mathrm{NO}$ at higher flow, $\pm 1.8 \mathrm{ppm} \mathrm{NO}$ at lower flow) were obtained in this study by accounting for the concentration and flow of the source-gas, as well as $\mathrm{V}_{\mathrm{T}}$ and inspiratory time of the patient (Equation 2). Measured concentrations tended to be somewhat higher than predicted, except in the sleep case. This is likely due to pooling of supplied gas in the upper airway near the end of expiration, which is not accounted for in the predictive calculation. Inhalation of gas that pooled in the nasal airway during exhalation is thought to explain the initial spike in tracheal gas concentration observed near the start of each inhalation in Figure 3.

Unlike NO concentration, NO mass flow past the trachea was highest for the exercise cases and lowest for the sleep and rest cases. Mass flow past the trachea averaged at 21.5 $\mathrm{mg} / \mathrm{h}$ for the higher NO supply flow and at $5.9 \mathrm{mg} / \mathrm{h}$ for the lower supply flow. The mass flow for the lower NO supply is comparable with the $75 \mu \mathrm{g} \mathrm{NO} / \mathrm{kg}$ ideal body weight $/ \mathrm{h}$ dose that was investigated in the INOvation-1 study of pulsed inhaled NO for treatment of pulmonary arterial hypertension. ${ }^{16}$ For example, a patient with $75 \mathrm{~kg}$ ideal body weight would receive $5.6 \mathrm{mg} / \mathrm{h}$, a dose similar to the mass flow reported in the present work. In this study, for both NO supply flows, the range of mass flow results was small across breathing patterns, lying within a range of \pm $5.4 \mathrm{mg} / \mathrm{h}$ for the high flow and $\pm 1.6 \mathrm{mg} / \mathrm{h}$ for the low flow. This supports the use of mass flow as a dose metric for noninvasive nasal NO administration because it suggests that, unlike NO concentration, for a fixed supply flow the mass flow at the trachea can be reasonably estimated without specific knowledge of the patient's breathing pattern.

Delivery efficiency, defined as the ratio of NO mass flow past the trachea to NO mass flow delivered through the cannula, showed a dependence on both breathing pattern and NO supply flow. For both NO supply flows, the exercise pattern had the highest delivery efficiency while sleep and rest had comparable delivery efficiencies. In addition, lower NO supply flows had higher delivery efficiencies. Across all cases studied, measured delivery efficiencies range between $37 \%$ and $53 \%$.

A limitation of the current work is that $\mathrm{NO}_{2}$ production could not be measured in vitro because $\mathrm{CO}_{2}$ was used as a surrogate gas to represent NO. However, using the methodology outlined by Tsukahara et al, ${ }^{35}$ an estimate of $\mathrm{NO}_{2}$ formed during the mixing of $\mathrm{NO}$ and $\mathrm{O}_{2}$ in the single-lumen cannula (Hudson RCI) was calculated. The maximum calculated $\mathrm{NO}_{2}$ production was $0.49 \mathrm{ppm}$ and represents conversion of just $0.21 \%$ of the NO in the flow, confirming that, even for a single-lumen continuous low-flow system, there would likely be insufficient residence time in the tubing for significant concentrations of $\mathrm{NO}_{2}$ to form. In addition, the NO flow is further diluted upon inhalation during the mixing of cannula gases with entrained room air.

An additional limitation is that the study focused on fixed inspiratory-expiratory ratios. With $\mathrm{V}_{\mathrm{T}}$ and breathing frequency held constant, it is likely that a change in the ratio would influence delivered tracheal NO concentrations and NO mass flow, a possibility that would be worth exploring in future studies. However, in a similar study assessing $\mathrm{O}_{2}$ delivery, ${ }^{24}$ concentrations that were delivered during patterns with varying inspiratory-expiratory ratios were well predicted using a flow-weighted formula similar 


\section{In Vitro Simulation of INO via Nasal Cannula}

to the one proposed in this study, which incorporated the inspiratory time (Equation 2).

Another limitation of this study is that the rigid airway model used does not rigorously reproduce the surface properties of the fluid-lined upper airways, nor does it include nasal hairs or cilia. While these fine geometric features may influence flow features in their close proximity, their influence on bulk flow is less certain. The assumption that the respiratory passages can be approximated as smooth surfaces allows representative boundary conditions to be met using modern three-dimensional printing processes, for which surface roughness is limited to a few micrometers. ${ }^{36}$ Our previous study reported by Chen et $\mathrm{al}^{22}$ assessed in vitro $\mathrm{O}_{2}$ concentrations measured in rigid airway models and noted that average inhaled $\mathrm{O}_{2}$ concentrations were in good agreement with values measured in vivo. ${ }^{37}$

\section{Conclusions}

In the present work, noninvasive administration of $\mathrm{NO}$ via nasal cannula was evaluated in vitro, using $\mathrm{CO}_{2}$ as a surrogate gas.Nasal cannula type had minimal effect on noninvasive continuous flow NO delivery, whereas breathing pattern and supply flow strongly influenced average inhaled NO concentrations evaluated at the trachea. Delivery efficiency was higher at lower supply flows and for breathing patterns that had a high minute volume. While average inhaled NO concentrations were reasonably well predicted with flow-weighted calculations, there was a wide variation in inhaled concentration among different breathing patterns. Inhaled mass flow of NO provides a more consistent dosing metric for noninvasive delivery of continuous flow NO because variation across breathing patterns was small.

\section{REFERENCES}

1. Frostell C, Fratacci M, Wain J, Jones R, Zapol W. Inhaled nitric oxide: a selective pulmonary vasodilator reversing hypoxic pulmonary vasoconstriction. Circulation 1991;83(6):2038-2047.

2. American Academy of Pediatrics. Committee on Fetus and Newborn. Use of inhaled nitric oxide. Pediatrics 2000;106(2):344-345.

3. Checchia P, Bronicki R, Goldstein B. Review of inhaled nitric oxide in the pediatric cardiac surgery setting. Pediatr Cardiol 2012;33 (4):493-505

4. Oz MC, Ardehali A. Collective review: perioperative uses of inhaled nitric oxide in adults. Heart Surg Forum 2004;7(6):E584-E589.

5. Creagh-Brown BC, Griffiths MJ, Evans TW. Bench-to-bedside review: inhaled nitric oxide therapy in adults. Crit Care 2009;13 (3):221.

6. Griffiths MJD, Evans TW. Inhaled nitric oxide therapy in adults. N Engl J Med 2005;353(25):2683-2695.

7. Martin AR, Jackson C, Fromont S, Pont C, Katz IM, Caillobotte G. An injection and mixing element for delivery and monitoring of inhaled nitric oxide. Biomed Eng Online 2016;15(1):103.

8. Bhatraju P, Crawford J, Hall M, Lang JD. Inhaled nitric oxide: current clinical concepts. Nitric Oxide 2015;50:114-128.
9. Tremblay J, Couture ÉJ, Albert M, Beaubien-Souligny W, ElmiSarabi M, Lamarche Y, et al. Noninvasive administration of inhaled nitric oxide and its hemodynamic effects in patients with acute right ventricular dysfunction. J. Cardiothorac. Vasc. Anesth 2019;33 (3):642-647.

10. Westfelt UN, Lundin S, Stenqvist O. Uptake of inhaled nitric oxide in acute lung injury. Acta Anaesthesiol Scand 1997;41(7):818-823.

11. Imanaka H, Hess D, Kirmse M, Bigatello LM, Kacmarek RM, Steudel W, Hurford WE. Inaccuracies of nitric oxide delivery systems during adult mechanical ventilation. Anesthesiology 1997;86(3):676-688.

12. Young JD, Roberts M, Gale LB. Laboratory evaluation of the INOvent nitric oxide delivery device. Br J Anaesth 1997;79(3):398401.

13. Tworetzky W, Bristow J, Moore P, Brook MM, Segal MR, Brasch $\mathrm{RC}$, et al. Inhaled nitric oxide in neonates with persistent pulmonary hypertension. Lancet 2001;357(9250):118-120.

14. Abman SH. Inhaled nitric oxide for the treatment of pulmonary arterial hypertension. In: Humbert M, Evgenov OV, Stasch J, editors. Pharmacotherapy of pulmonary hypertension: handbook of experimental pharmacology, vol 218. Berlin: Springer-Verlag; 2013; 257276.

15. Barst RJ, Channick R, Dunbar I, Goldstein B. Clinical perspectives with long-term pulsed inhaled nitric oxide for the treatment of pulmonary arterial hypertension. Pulm Circ 2012;2(2):139-147.

16. Quinn D, on behalf of Bellerophon Pulse Technologies. Clinical study of pulsed, inhaled nitric oxide versus placebo in symptomatic subjects with PAH (INOvation-1). Aug 6, 2019. Available at: https:// clinicaltrials.gov/ct2/show/study/NCT02725372. Accessed September $5,2019$.

17. Tiep B, Carter R. Oxygen conserving devices and methodologies. Chron Respir Dis 2008;5(2):109-114.

18. Martin AR, Jackson C, Katz IM, Caillibotte G. Variability in uptake efficiency for pulsed versus constant concentration delivery of inhaled nitric oxide. Med Gas Res 2014;4(1):1.

19. Hajian B, De Backer J, Vos W, Van Holsbeke C, Ferreira F, Quinn DA, et al. Pulmonary vascular effects of pulsed inhaled nitric oxide in COPD patients with pulmonary hypertension. Int $\mathrm{J}$ Chron Obstruct Pulmon Dis 2016;11:1533-1541.

20. Yaacoby-Bianu K, Gur M, Toukan Y, Nir V, Hakim F, Geffen Y, et al. Compassionate nitric oxide adjuvant treatment of persistent mycobacterium infection in cystic fibrosis patients. Pediatr Infect Dis J 2018;37(4):336-338

21. Berra L, Lei C, Su B, Dong H, Fakhr BS, Grassi LG, et al. Protocol for a randomized controlled trial testing inhaled nitric oxide therapy in spontaneously breathing patients with COVID-19. medRxiv 2020 [Epub ahead of print].

22. Chen JZ, Katz IM, Pichelin M, Zhu K, Caillibotte G, Noga ML, et al. Comparison of pulsed versus continuous oxygen delivery using realistic adult nasal airway replicas. Int J Chron Obstruct Pulmon Dis 2017;12:2559-2571

23. Chen JZ, Katz IM, Pichelin M, Zhu K, Caillibotte G, Finlay WH, et al. In vitro-in silico comparison of pulsed oxygen delivery from portable oxygen concentrators versus continuous flow oxygen delivery. Respir Care 2019;64(2):117-129.

24. Katz I, Chen J, Duong K, Zhu K, Pichelin M, Caillibotte G, et al. Dose variability of supplemental oxygen therapy with open patient interfaces based on in vitro measurements using a physiologically realistic upper airway model. Respir Res 2019;20(1):149.

25. Duprez F, Mashayekhi S, Cuvelier G, Legrand A, Reychler G. A new formula for predicting the fraction of delivered oxygen during lowflow oxygen therapy. Respir Care 2018;63(12):1528-1534.

26. Golshahi L, Noga ML, Thompson RB, Finlay WH. In vitro deposition measurement of inhaled micrometer-sized particles in extrathoracic 


\section{In Vitro Simulation of INO via Nasal Cannula}

airways of children and adolescents during nose breathing. J Aerosol Sci 2011;42(7):474-488

27. US Food and Drug Administration. Guidance document for premarket notification submissions for nitric oxide delivery apparatus, nitric oxide analyzer and nitrogen dioxide analyzer. 2000. Available at: https:// www.fda.gov/regulatory-information/search-fda-guidance-documents/ guidance-document-premarket-notification-submissions-nitricoxide-delivery-apparatus-nitric-oxide. Accessed August 4, 2020.

28. Finlay WH. The mechanics of inhaled pharmaceutical aerosols: an introduction. San Diego: Academic Press; 2001.

29. Chatila W, Nugent T, Vance G, Gaughan J, Criner GJ. The effects of high-flow vs low-flow oxygen on exercise in advanced obstructive airways disease. Chest 2004;126(4):1108-1115.

30. Hudgel DW, Martin RJ, Capehart M, Johnson B, Hill P. Contribution of hypoventilation to sleep oxygen desaturation in chronic obstructive pulmonary disease. J Appl Physiol Respir Environ Exerc Physiol 1983;55(3):669-677.

31. Langer AW, Hutcheson JS, Charlton JD, McCubbin JA, Obrist PA, Stoney CM. On-line minicomputerized measurement of cardiopulmonary function on a breath-by-breath basis. Psychophysiology 1985;22(1):50-58.
32. Taylor JR. An introduction to error analysis: the study of uncertainties in physical measurements. Sausalito, CA: University Science Books; 1997:327.

33. Ghadimi K, Rajagopal S. Nasally inhaled nitric oxide for sudden rightsided heart failure in the intensive care unit: no time like the present. J Cardiothorac Vasc Anesth 2019;33(3):648-650.

34. DiBlasi RM, Dupras D, Kearney C, Costa E Jr, Griebel JL. Nitric oxide delivery by neonatal noninvasive respiratory support devices. Respir Care 2015;60(2):219-230.

35. Tsukahara H, Ishida T, Mayumi M. Gas-phase oxidation of nitric oxide: chemical kinetics and rate constant. Nitric Oxide 1999;3(3):191198.

36. Tavernini S, Church TK, Lewis DA, Martin AR, Finlay WH. Scaling an idealized infant nasal airway geometry to mimic inertial filtration of neonatal nasal airways. J Aerosol Sci 2018;118:14-21.

37. O’Reilly Nugent A, Kelly PT, Stanton J, Swanney MP, Graham B, Beckert L. Measurement of oxygen concentration delivered via nasal cannulae by tracheal sampling. Respirology 2014;19(4):538543. 